\title{
Reproductive performance of Coopworth ewes following oral doses of zearalenone before and after mating
}

\author{
J. F. Smith, M. E. di Menna and L. T. McGowan \\ Ministry of Agriculture and Fisheries, MAFTech North, Ruakura Agricultural Centre, Private Bag, \\ Hamilton, New Zealand
}

\begin{abstract}
Summary. The reproductive performance of Coopworth ewes after administration of zearalenone was determined in two trials. In Trial 1 , zearalenone was administered to groups of 33 ewes at rates of $0,1 \cdot 5,3 \cdot 0,6 \cdot 0,12 \cdot 0$ and $24 \cdot 0 \mathrm{mg} /$ ewe/day for 10 days, starting on Day 7 of the oestrous cycle before mating. There was a linear decline $(P<0.001)$ in ovulation rate with dose of zearalenone; also cycle length decreased and duration of oestrus increased with increasing dose levels. Reductions in the incidence of ovulation and in fertilization were seen only at doses of 12 and $24 \mathrm{mg}$. In Trial 2, groups of 50 ewes were given the same range of doses of zearalenone for 10 days, starting 5 days after mating to entire rams. There was no effect of zearalenone treatment after mating on pregnancy rate or embryonic loss. These results indicate that the effects of zearalenone, administered orally, on ewe reproduction, at the dose levels examined, were restricted to ewes exposed before mating. Intakes of zearalenone of $3 \mathrm{mg} / \mathrm{ewe} / \mathrm{day}$ or more during this period would be reflected as depressed ovulation rates and lower lambing percentages.
\end{abstract}

Keywords: zearalenone; ewes; ovulation; oestrus; fertility

\section{Introduction}

Large-spored fusaria are a common component of the mycoflora of leaves of pasture in the North Island of New Zealand (di Menna \& Parle, 1970). They are present in greatest numbers in late summer and autumn (February to April), and counts of $10^{4}$ to $10^{7}$ Fusarium macroconidia/g wet weight of leaves have been recorded. Some Fusarium spp. produce metabolites which affect animals, among them the F-2 toxin or zearalenone [6-(10-hydroxy-6-oxo-trans-1-undecenyl)- $\beta$ resorcyclic acid-lactone] which has oestrogenic activity (Christensen et al., 1965). Zearalenone has often been reported in Fusarium-infected grains and feedstuffs prepared from them and also from infected hay (Mirocha et al., 1968). Various Fusarium strains isolated from New Zealand pastures have been shown to produce zearalenone when cultured (di Menna et al., 1985; Gallagher, 1985). There have also been reports of the presence of zearalenone in pasture infected with Fusarium spp. (di Menna et al., 1985, 1987).

Zearalenone has oestrogenic properties (Mirocha et al., 1978; Blankenship et al., 1982) and detrimental effects on the reproductive performance of sows and cows have been reported (Mirocha et al., 1968; Kurtz et al., 1969; Chang et al., 1979; Long et al., 1983; Diekman \& Long, 1984). On some New Zealand farms there are unexplained shortfalls in the reproductive performance of ewes and it was thought possible that Fusarium spp., at their peak in pasture at the time ewes are mated, might produce sufficient zearalenone to affect ewe fertility (Jagusch et al., 1986). Reports of the effects of zearalenone on reproduction of sheep are sparse and tend to be associated with its effect on the pregnant animal (Mitton et al., 1975). The administration of $25 \mathrm{mg}$ zearalenone/ewe/day for 10 days before oestrus caused almost complete disruption of reproduction (Smith et al., 1986). 
However, the levels of zearalenone reported in pasture $(0.4$ to $4.0 \mathrm{mg} / \mathrm{kg})$ would generally result in intakes much lower than this and few data are available on the effects of lower levels of zearalenone on reproduction in sheep. This report deals with two trials that were conducted to examine the effects of low doses of zearalenone administered before or after mating on the reproductive performance of ewes.

\section{Materials and Methods}

\section{Animals and trial design}

Trial 1. The 198 Coopworth ewes (5- and 6-year-olds) were allocated on the basis of age, liveweight and previous reproductive performance to 6 groups. Ewes were given per os $0.0,1 \cdot 5,3 \cdot 0,6 \cdot 0,12 \cdot 0$ or $24.0 \mathrm{mg}$ zearalenone/day (International Minerals and Chemical Corporation, Terre Haute, IN, USA) in $10 \mathrm{ml}$ of a $30 \%$ (v:v) solution of ethanol and water. Ewes were yarded and drenched at 08:00 h each day. Groups were treated in order of increasing dose and this order was maintained throughout the trial.

Ewes were treated with intravaginal synchronization devices (CIDR, type G; Carter Holt Harvey, Plastic Products Group Limited, Hamilton, New Zealand). These are ' $Y$ '-shaped devices consisting of a silicone elastomer coating over a nylon spine and containing $0.3 \mathrm{~g}$ progesterone $(9 \% \mathrm{w}: \mathrm{w})$. They were inserted for 14 days to synchronize oestrus and ewes were dosed with their respective treatments for a period of 10 days starting on Day 7 of the cycle after CIDR removal. An initial pre-treatment ovulation rate for each group was determined by laparoscopic examination on the day preceding treatment (Day 6 of cycle). After 5 days of treatment the groups of ewes were each run with 3 entire rams fitted with harnesses and crayons and inspected twice daily $(08: 00 \mathrm{~h}$ and 16:00 h) for mating marks.

Once the first ewe in each group had shown oestrus then the rams were changed for another team of 3 entire rams with a different coloured crayon. This procedure was continued until ewes were not marked for 3 consecutive inspections. When necessary crayon marks were removed by trimming the wool.

At 7 days after the final dosing all ewes were slaughtered in the Ruakura Abattoir. The reproductive tract was removed and the ovaries examined for number of corpora lutea. The oviducts and uterus were flushed and ova were collected and examined for fertilization and stage of development.

At the time of slaughter the weights of the carcass, liver, ovaries and uterus and oviducts were recorded.

Trial 2. The 300 Coopworth ewes (4- and 5-year-olds) were allocated to 6 groups and given the same range of zearalenone doses for 10 days starting 5 days after mating. Ewes were treated with CIDRs to synchronize oestrus and run with 5 entire rams per group, commencing 15 days after CIDR removal (i.e. at the second oestrus). Ovulation rate was determined via laparoscopy immediately before treatment. Returns to service were recorded daily during and for 30 days after treatment. Fetal numbers were determined, by real-time ultrasonic scanning, 50 days after mating and detailed lambing records were collected.

\section{General}

The incidence of oestrus after CIDR removal in both trials was determined using vasectomized rams fitted with harnesses and crayons and run with ewes in one group at a ratio of 1:15. Return to service, at the third oestrus after synchronization, in Trial 2 was determined in similar manner.

Ewe liveweights were recorded, following $18 \mathrm{~h}$ removal from feed and water, at the time of laparoscopy and also before slaughter.

Before laparoscopic examination ewes were given an intramuscular injection of xylazine (Rompun), $0 \cdot 2 \mathrm{mg} / \mathrm{kg}$.

Ewes were grazed on rye grass/white clover pasture at an allowance of $4.0 \mathrm{~kg}$ green dry matter (DM)/ewe/day. Pasture yields were assessed visually. Paddocks were sprayed with benlate ( $50 \%$ benomyl: methyl 1 (butylcarbamoyl)2-benzimidazolecarbamate; E. I. Dupont De Menours and Co. (Inc.), Wilmington, DE, USA) at $400 \mathrm{~g} / 10^{4} / \mathrm{m}^{2}$ for fungal control and numbers of Fusarium macroconidia and Pithomyces chartarum spores were monitored 3 times/ week. Leaf samples, collected from the paddock being grazed on the collection date and from the paddock next in rotation, were shaken with 10 times their weight of water and the spores in $2 \times 10^{-3} \mathrm{ml}$ wash water were counted in haemocytometer slides. Pasture zearalenone levels were monitored throughout the trial. The pasture samples collected were air-dried and then ground. Sub-samples $(1.0 \mathrm{~g})$ were extracted with dichloromethane, the extracts were cleaned by a base-acid partitioning procedure and then analysed by reversed-phase high-performance liquid chromatography using fluorescence detection (di Menna et al., 1987).

The trials were conducted during the period February to September 1986 (Trial 1 from 14 February to 27 March and Trial 2 from 28 February to 31 August) at the Ruakura Animal Research Station, Hamilton, New Zealand $\left(37^{\circ} 46^{\prime} \mathrm{S}, 175^{\circ} 20^{\prime} \mathrm{E}\right.$, elevation of $\left.40 \mathrm{~m}\right)$.

The experiments were conducted with the approval of the Ruakura Animal Ethics Committee under the "Animal Protection Regulations (code of ethical conduct) New Zealand'oaded from Bioscientifica.com at 04/26/2023 01:27:40PM 


\section{Statistical analyses}

Analyses were performed using the "GENSTAT V" programme (Lawes Agricultural Trust-Rothamsted Experimental Station). Investigations of the dose response were conducted using analysis of variance with adjustment for initial liveweight as a co-variate. Poisson and binomial models were used for number of ovulations and the percentage data on egg recovery and fertilization respectively.

\section{Results}

\section{Pasture intake, spore counts and zearalenone content}

The average pre-grazing pasture yield was $2400 \mathrm{~kg} \mathrm{DM} / 10^{4} / \mathrm{m}^{2}$, containing $85 \%$ green material and the average post-grazing residual was $1500 \mathrm{~kg} \mathrm{DM} / 10^{4} / \mathrm{m}^{2}$. Ewes were rotationally grazed with 3 shifts/week at an intensity of $250 \mathrm{ewes} / 10^{4} / \mathrm{m}^{2}$. This gave an average estimated intake of $1.5 \mathrm{~kg}$ $\mathrm{DM} /$ day/ewe.

The highest count of Fusarium macroconidia was $180000 / \mathrm{g}$ leaves (wet weight) on 4 April 1986 and of Pithomyces chartarum spores 85000 on 28 May 1986 but counts were usually low and macroconidia were undetectable or at their lowest detectable level $(5000 / \mathrm{g})$ at 16 of the 54 sampling times and $<50000 / \mathrm{g}$ on a further 22 occasions. $P$. chartarum spores were below or at the limit of detection on 35 of the 54 sampling times. The highest level of zearalenone detected was $0.6 \mathrm{mg} / \mathrm{kg}$ $\mathrm{DM}$ of leaf material and it was either non-detectable or below $0.05 \mathrm{mg} / \mathrm{kg} \mathrm{DM}$ on 38 of the 54 occasions that samples were taken.

\section{Reproductive performance}

Trial 1. There were significant $(P<0.001)$ effects of dose of zearalenone on cycle length (days between successive oestrous periods) and on the duration of oestrus after treatment. Cycle length decreased and duration increased with increasing dose of zearalenone (Table I). These changes were of a linear nature (Table 3) and are illustrated in Fig. 1. There was no effect of zearalenone on the incidence of oestrus with all ewes exhibiting oestrus after treatment. However, there was a significant $(P<0.001)$ effect of dose of zearalenone on the proportion of ewes ovulating after treatment with a marked reduction at the higher $(12.0$ and $24.0 \mathrm{mg})$ dose levels (Table 1). The ovulation rate or number of ovulations per ewe examined was also affected by dose of zearalenone and showed a linear $(P<0.001)$ decline (Table 1; Table 3; Fig. 1) with increasing dose. This was reflected in the progressive decline in change of ovulation rate with increasing dose of zearalenone (Table 1).

Table 1. Effect of dose of zearalenone administered before mating on various reproductive parameters of Coopworth ewes (33/group)

\begin{tabular}{|c|c|c|c|c|c|c|c|}
\hline & \multicolumn{7}{|c|}{ Dose of zearalenone (mg/ewe/day) } \\
\hline & $0 \cdot 0$ & $1 \cdot 5$ & $3 \cdot 0$ & $6 \cdot 0$ & $12 \cdot 0$ & $24 \cdot 0$ & s.e.d. $\dagger$ \\
\hline Cycle length (days) & $15 \cdot 9$ & $15 \cdot 9$ & $15 \cdot 6$ & $15 \cdot 2$ & $14 \cdot 9$ & $14 \cdot 0$ & $0 \cdot 28$ \\
\hline Duration of oestrus (h) & 14.9 & $18 \cdot 0$ & $15 \cdot 0$ & $22 \cdot 1$ & $32 \cdot 0$ & $41 \cdot 8$ & $5 \cdot 13$ \\
\hline Ewes ovulating after treatment $(\%)$ & 100 & 94 & 94 & 100 & 64 & 61 & $8 \cdot 0$ \\
\hline $\begin{array}{l}\text { Ovulation rate }(\mathrm{OR})^{*} \\
\text { Before treatment } \\
\text { After treatment } \\
\text { Difference }(\Delta O R)\end{array}$ & $\begin{array}{r}2.12 \\
2.00 \\
-0.12\end{array}$ & $\begin{array}{r}1.88 \\
1.73 \\
-0.15\end{array}$ & $\begin{array}{r}2.12 \\
1.66 \\
-0.46\end{array}$ & $\begin{array}{r}2.00 \\
1.53 \\
-0.47\end{array}$ & $\begin{array}{r}2.03 \\
1.03 \\
-1.00\end{array}$ & $\begin{array}{r}2.00 \\
0.82 \\
-1 \cdot 18\end{array}$ & $0 \cdot 19$ \\
\hline Ewes yielding ova/ewes ovulating (\%) & $65 \cdot 6$ & $74 \cdot 2$ & $76 \cdot 7$ & $73 \cdot 3$ & $76 \cdot 2$ & $70 \cdot 0$ & $12 \cdot 7$ \\
\hline $\begin{array}{l}\text { Ewes yielding fertilized ova/ewes } \\
\text { yielding ova }(\%)\end{array}$ & $81 \cdot 0$ & $87 \cdot 0$ & $87 \cdot 0$ & $81 \cdot 8$ & $68 \cdot 8$ & $71 \cdot 4$ & $13 \cdot 5$ \\
\hline
\end{tabular}

*No. of ovulations per ewe examined.

† Standard error of difference between two means. 


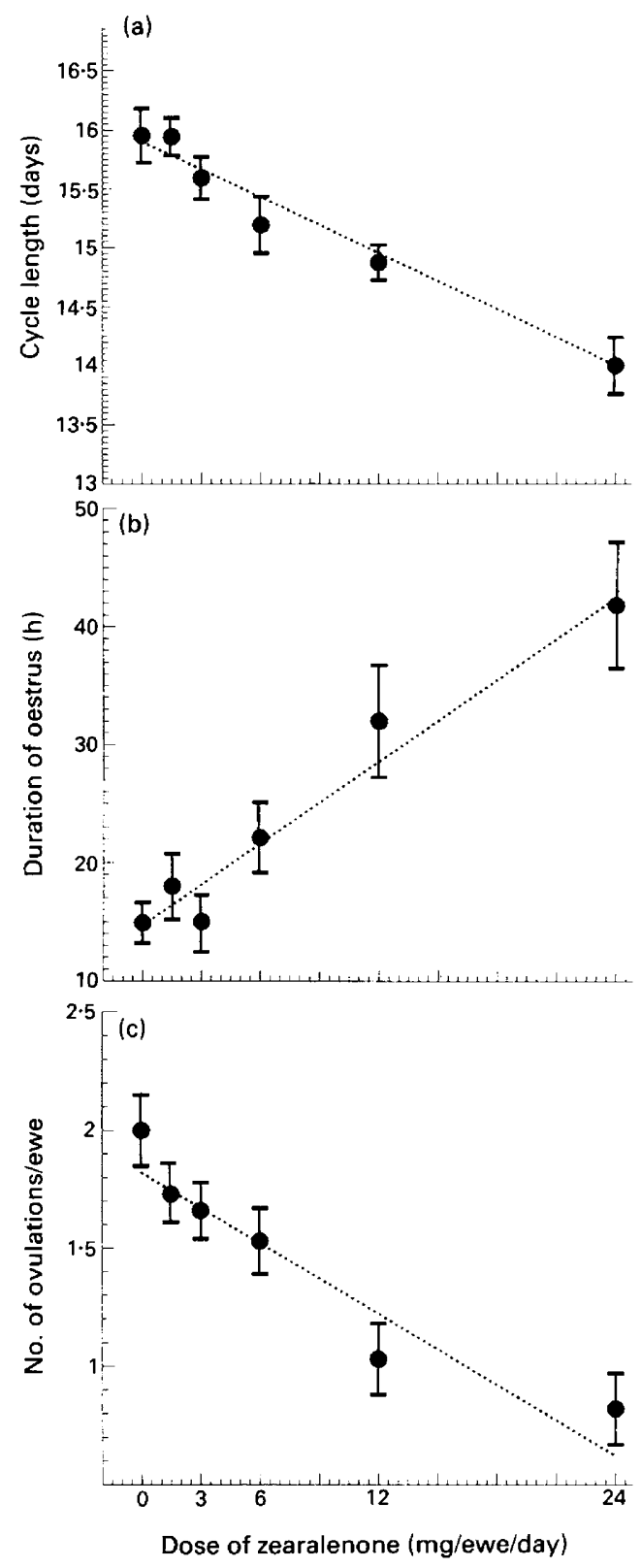

Fig. 1. Effect in ewes of dose of zearalenone ( $\mathrm{mg} / \mathrm{ewe} /$ day) before mating on (a) cycle length, (b) duration of oestrus, and (c) no. of ovulations per ewe. Values are means ( \pm s.e.) and the lines are derived from the regression equations in Table 3.

There were no significant effects of zearalenone on the proportion of ewes yielding ova of those ewes ovulating $(72.6 \%)$ or on the proportion of ewes yielding fertilized ova of those yielding ova $(80 \cdot 7 \%$; Table 1$)$.

Zearalenone dose had significant effects on liver weight $(P<0.001)$, ovary weight $(P<0.001)$ and weight of uterus and oviducts $(P<0.01)$ but not on the carcass weight (Table 2). There was no effect of dose on ewe liveweight after treatment or on liveweight change from before to after treatment. 
Table 2. Effect of dose of zearalenone administered before mating on ewe liveweight, weight of carcass and weight of various organs of Coopworth ewes (33/group)

\begin{tabular}{lccccccc}
\hline & \multicolumn{7}{c}{ Dose of zearalenone (mg/ewe/day) } \\
\cline { 2 - 8 } Parameter & 0.0 & 1.5 & 3.0 & 6.0 & 12.0 & 24.0 & s.e.d. $\dagger$ \\
\hline Ewe liveweight (kg) & 51.9 & 52.5 & 51.9 & 52.5 & 52.1 & 52.8 & 0.6 \\
$\quad$ Before treatment & 55.2 & 56.1 & 55.1 & 55.7 & 55.0 & 55.7 & 0.6 \\
$\quad$ After treatment & 25.5 & 26.4 & 26.1 & 26.6 & 26.1 & 26.5 & 0.5 \\
Carcass weight (kg) & 0.95 & 0.93 & 0.96 & 1.01 & 1.02 & 1.03 & 0.03 \\
Liver weight (kg) & 3.9 & 4.1 & 3.7 & 3.5 & 3.4 & 3.1 & 0.27 \\
Ovary weight (g) & 55.4 & 58.3 & 60.5 & 61.2 & 63.0 & 64.8 & 2.94 \\
Uterus weight (g) & & & & & & \\
\hline
\end{tabular}

†Standard error of difference between two means.

Table 3. Simple linear regression equations for dose of zearalenone $(x)$ administered before mating on various response variables $(y)$

\begin{tabular}{|c|c|c|c|c|}
\hline Response variable & Equation & $r^{2}$ & $\begin{array}{l}\text { Significance } \\
(\mathrm{df}=195)\end{array}$ & rsd $\dagger$ \\
\hline Cycle length (days) & $y=15.9-0.08( \pm 0.01) x$ & 0.267 & $* * *$ & 1.13 \\
\hline Duration of oestrus (h) & $y=14.7+1.16( \pm 0.18) x$ & $0 \cdot 188$ & $* * *$ & $20 \cdot 65$ \\
\hline $\begin{array}{l}\text { Ovulation rate } \\
\text { (after treatment) }\end{array}$ & $y=1.82-0.05( \pm 0.008) x$ & $0 \cdot 163$ & $* * *$ & 0.57 \\
\hline Liver weight $(\mathrm{kg})$ & $y=0.95+0.004( \pm 0.001) x$ & 0.061 & $* * *$ & $0 \cdot 12$ \\
\hline Ovary weight (g) & $y=3.87-0.04( \pm 0.008) x$ & 0.074 & $* * *$ & 0.89 \\
\hline Uterine weight (g) & $y=59 \cdot 1+0 \cdot 24( \pm 0 \cdot 11) x$ & 0.037 & $* *$ & $11 \cdot 91$ \\
\hline
\end{tabular}

†Residual standard deviation.

${ }^{* *} P<0.01 ;{ }^{* * *} P<0.001$.

Table 4. Effect of dose of zearalenone administered after mating on reproductive parameters of Coopworth ewes (50/group)

\begin{tabular}{lccccccc}
\hline & \multicolumn{7}{c}{ Dose of zearalenone (mg/ewe/day) } \\
\cline { 2 - 8 } & 0.0 & 1.5 & 3.0 & 6.0 & 12.0 & 24.0 & Total \\
\hline No. of ewes (EJ)* with males & 50 & 48 & 50 & 50 & 47 & 50 & 295 \\
Total no. of ovulations (OT) & 96 & 95 & 90 & 94 & 93 & 102 & 570 \\
Ovulation rate (OR) & 1.92 & 1.98 & 1.80 & 1.88 & 1.98 & 2.04 & 1.93 \\
No. of ewes lambed 1st cycle (EL) & 33 & 31 & 39 & 38 & 35 & 35 & 211 \\
Conception rate (\%) & 66.0 & 64.6 & 78.0 & 76.0 & 74.5 & 70.0 & 71.5 \\
No. of lambs born (LB) & 56 & 52 & 62 & 58 & 55 & 62 & 345 \\
LB/EJ & 1.12 & 1.08 & 1.24 & 1.16 & 1.17 & 1.24 & 1.17 \\
LB/EL & 1.70 & 1.68 & 1.59 & 1.53 & 1.57 & 1.77 & 1.64 \\
No. of ovulations of ewes lambing & 63 & 63 & 72 & 72 & 66 & 75 & 411 \\
(O.EL) & 1.91 & 2.03 & 1.85 & 1.89 & 1.89 & 2.14 & 1.95 \\
Ovulation rate (OR.EL) & & & & & & & \\
\hline
\end{tabular}

*No. of ewes kept with rams and present at lambing. 
Table 5. Effect of dose of zearalenone administered after mating on levels of ova wastage in Coopworth ewes (50/group)

\begin{tabular}{|c|c|c|c|c|c|c|c|}
\hline & \multicolumn{7}{|c|}{ Dose of zearalenone (mg/ewe/day) } \\
\hline & 0.0 & $1 \cdot 5$ & $3 \cdot 0$ & $6 \cdot 0$ & $12 \cdot 0$ & $24 \cdot 0$ & Total \\
\hline Full loss* & 33 & 32 & 18 & 22 & 27 & 27 & 159 \\
\hline As $\%$ of OT $\dagger$ & $34 \cdot 4$ & $33 \cdot 7$ & $20 \cdot 0$ & $23 \cdot 4$ & $29 \cdot 0$ & $26 \cdot 5$ & $27 \cdot 9$ \\
\hline Partial loss $\ddagger$ & 7 & 11 & 10 & 14 & 11 & 13 & 66 \\
\hline As $\%$ of OT & $7 \cdot 3$ & $11 \cdot 6$ & $11 \cdot 1$ & 14.9 & 11.8 & $12 \cdot 7$ & 11.6 \\
\hline As $\%$ of O.EL§ & $11 \cdot 1$ & $17 \cdot 5$ & 13.9 & $19 \cdot 4$ & $16 \cdot 7$ & $17 \cdot 3$ & $16 \cdot 1$ \\
\hline Total loss & 40 & 43 & 28 & 36 & 38 & 40 & 225 \\
\hline As $\%$ of OT & $41 \cdot 7$ & $45 \cdot 3$ & $31 \cdot 1$ & $38 \cdot 3$ & $40 \cdot 9$ & $39 \cdot 2$ & $39 \cdot 5$ \\
\hline
\end{tabular}

*No. of ova shed by ewes failing to lamb.

†Total number of ovulations of ewes placed with males.

$\ddagger$ Difference between no. of lambs born and no. of ovulations for those ewes lambing.

$\S$ No. of ovulations of ewes lambing.

बFull loss + partial loss.

The changes in organ weight had significant linear components of dose (Table 3).

Trial 2. There were no significant effects of dose of zearalenone administered after mating on the proportion of ewes which bore a lamb, number of lambs born or on various measures of embryonic or ova wastage. Of the 300 ewes placed with males 295 survived to lambing time. These ewes had a mean ovulation rate of 1.93 and $71.5 \%$ of them conceived and lambed to the one synchronized cycle of mating with entire rams. There was an average of 1.64 lambs born per ewe lambing (Table 4).

Subtraction of the number of lambs born from the initial ovulation rate indicates a total ova wastage of $39 \cdot 5 \%$ (Table 5 ).

Examination of the cycle length of the 53 ewes exhibiting a return oestrus showed that only 3 ewes $(6 \%)$ had cycles outside the normal 16-18-day range. These 3 all had 15-day cycles and the ewes were in the $24 \mathrm{mg}$ ( 1 ewe) and $12 \mathrm{mg}$ ( 2 ewes) dose groups. The mean cycle length for these 2 groups $(16.4 \pm 0.3$ days $)$ was significantly $(P<0.05)$ shorter than that for the other groups $(17 \cdot 1 \pm 0 \cdot 2$ days $)$.

\section{Discussion}

The virtual absence of zearalenone from the pasture grazed in the two experiments indicates that the effects of zearalenone dosage are unlikely to have been confounded by exposure to pasture zearalenone. The very low levels of Pithomyces chartarum spores also indicate that the results are unlikely to be confounded by sporodesmin toxicity (facial eczema disease), which has been shown to depress ewe fertility (Smeaton et al., 1985).

Treatment of ewes before mating with zearalenone markedly affected their reproductive performance, the most noticeable effect being a linear decline in ovulation rate with an increasing dose of zearalenone. At the lower doses this was due to a reduction in the proportion of ewes with multiple ovulations while the higher doses $(12.0$ and $24.0 \mathrm{mg})$ caused a proportion of the ewes to become anovulatory. The depression in ovulation rate at the high dose is similar to that reported previously for a $25-\mathrm{mg}$ dose (Smith et al., 1986). The reduction in numbers of ewes with multiple ovulations at the lower doses is of sufficient magnitude to explain the reduced twinning in ewes grazed on zearalenone-contaminated pastures (Jagusch et alo, 1986).entifica.com at 04/26/2023 01:27:40PM 
The linear reduction in ovulation rate with increasing dose is similar to that reported for increasing doses of coumestrol (Smith et al., 1979). Comparison of those data with the results in the present trial indicates that zearalenone has about 10 times the activity of coumestrol. The most likely mechanism of action, causing the decrease in ovulation rate, is through a reduction in plasma FSH concentrations due to increased oestrogenic negative feedback on the pituitary (Smith et al., 1987).

The lack of a significant effect on fertilization rate in the present trial, even at higher doses, contrasts with that reported by Smith et al. (1986) who found a reduction in the number of ewes yielding fertilized embryos when dosed with $25 \mathrm{mg}$ zearalenone, even though similar mating management and ram:ewe ratios were used in both experiments. This is a surprising result considering previously reported effects of oestrogen on fertilization and sperm transport (Croker et al., 1975) and there is no obvious explanation, although these data indicate a tendency for reduced fertility at the higher doses. In neither experiment was there any effect of zearalenone before mating on subsequent embryo recovery rates. The decrease in cycle length and increase in duration of oestrus with increasing dose of zearalenone confirm its oestrogenic action in the ewe (Fletcher \& Lindsay, 1971). This is further supported by the increase in uterine weight and reduction in ovarian weight recorded. Enlargement of the reproductive tract and prolonged oestrous activity has also been reported in sows exposed in zearalenone (Chang et al., 1979). However, the shortened cycle length of the ewes contrasts with markedly extended cycles reported for zearalenone-treated sows (Edwards et al., 1987; Flowers et al., 1987) although the levels of zearalenone intake were similar. This indicates the possibility of different roles for oestrogen in the luteolytic process of the two species.

The failure of zearalenone, administered between Days 5 and 15 after mating at the dose levels used in Trial 2, to affect the number of ewes pregnant and their lambing rate is a most important finding. It indicates that, under grazing conditions and exposure to zearalenone at the levels reported in New Zealand pasture (di Menna et al., 1987), most of the decreased reproductive performance is due to pre-mating exposure and reduction in ovulation rate. The lack of effect of zearalenone on embryonic loss in the ewe is in marked contrast to that reported for gilts and sows (Long et al., 1983, 1988; Long \& Diekman, 1984) in which severe embryonic wastage was observed. This could possibly be a reflection of dose of zearalenone given as, in general, the levels causing the effect in sows were higher than those given to the ewes in the present trial. However in one experiment (Long \& Diekman, 1984) a significant depression was obtained in embryo survival of gilts given $27 \mathrm{mg}$ zearalenone per day from Days 2 to 15 after mating. Expression of that dosage in terms of $\mathrm{mg}$ zearalenone per $\mathrm{kg}$ liveweight $(0 \cdot 24)$ would be equivalent to ewes receiving the $12 \mathrm{mg}$ dose in the present trial $(0 \cdot 23)$. These results again suggest different sensitivity to and/or mechanisms of action of oestrogenic compounds on the reproductive processes of the two species.

The results of the present experiments indicate that a zearalenone intake at the levels recorded in pasture for a brief period before mating will cause a reduction in the lambing percentage of exposed ewes. How transient this effect is and what would be the effect of longer periods of exposure are questions that require further investigation.

We thank Professor C. J. Mirocha (University of Minnesota) for the supply of pure zearalenone; Dr D. Lauren and Mr M. P. Agnew for the zearalenone analyses of pasture; Mr J. Parr and the staff of the Sheep Unit Ruakura for management of the experimental animals; and $\mathrm{Mr}$ D. M. Duganzich for statistical analyses.

\section{References}

Blankenship, L.T., Dickey, J.F., Bodine, A.B. \& Clemson, S.C. (1982) In vitro mycotoxin binding to bovine uterine steroid hormone receptors. Theriogenology 17,03250331. from Bioscientifica.com at 04/26/2023 01:27:40PM via free access 
Chang, K., Kurtz, H.J. \& Mirocha, C. J. (1979) Effects of the mycotoxin zearalenone on swine reproduction. Am. J. vet. Res. 40, 1260-1267.

Christensen, C.M., Nelson, G.H. \& Mirocha, C.J. (1965) Effect on the whole rat uterus of a toxic substance isolated from Fusarium. Appl. Microbiol. 13, 653-659.

Croker, K.P., Robinson, T.J. \& Shelton, J.N. (1975) The effect of oestrogen administered during the progestational phase of the cycle on transport of spermatozoa in ewes. J. Reprod. Fert. 44, 11-23.

Diekman, M.A. \& Long, G.G. (1984) Mycotoxins and reproduction in swine. Anim. nut. Health July/Aug. $22-28$.

di Menna, M.E. \& Parle, J.N. (1970) Moulds on leaves of perennial rye grass and white clover. N.Z. Jl agric. Res. 13, 57-58.

di Menna, M.E., Lauren, D.R. \& Holland, P.T. (1985) Presence of zearalenone in New Zealand pasture leaves. N.Z. vet. J. 33, 193.

di Menna, M.E., Lauren, D.R., Poole, P.R., Mortimer, P.H., Hill, R.A. \& Agnew, M.P. (1987) Zearalenone in New Zealand pasture herbage and the mycotoxinproducing potential of Fusarium species from pasture. N.Z. Jl agric. Res. 30, 499-504.

Edwards, S., Cantley, T.C., Rottinghaus, G.E., Osweiler, G.D. \& Day, B.N. (1987) The effects of zearalenone on reproduction in swine I. The relationship between ingested zearalenone dose and anestrus in nonpregnant, sexually mature gilts. Theriogenology $\mathbf{2 8}$, 43- 49 .

Fletcher, I.C. \& Lindsay, D.R. (1971) Effect of oestrogen on oestrous behaviour and its variation with season in the ewe. J. Endocr. 50, 685-696.

Flowers, B., Cantley, T. \& Day, B.N. (1987) A comparison of effects of zearalenone and estradiol benzoate on reproductive function during the estrous cycle in gilts. J. Anim. Sci. 65, 1576-1584.

Gallagher, R.T. (1985) On the oestrogenic mycotoxin zearalenone, and the pasture fungus Fusarium culmorum. N.Z. vet. J. 33, 37-38.

Jagusch, K.T., Gray, M.H., Maclean, K.S., Towers, N.R., di Menna, M.E. \& McMillan, W.H. (1986) The cause of reproductive loss in Gisborne-East Coast ewe flocks. Proc. N.Z. Soc. Anim. Prod. 46, 251-253.
Kurtz, J.J., Nairn, M.E., Nelson, G.H., Christensen, C.M. \& Mirocha, C.J. (1969) Histological changes in the genital tracts of swine fed estrogenic mycotoxin. Am. J. vet. Res. 30, 552-556.

Long, G.G. \& Diekman, M.A. (1984) Effect of purified zearalenone on early gestation in gilts. J. Anim. Sci. 59, $1662-1670$.

Long, G.G., Diekman, M.A., Tuite, J.F., Shannon, G.M. \& Vesonder, R.F. (1983) Effect of Fusarium roseum (Gibberella zea) on pregnancy and the estrous cycle in gilts fed molded corn on days 7-17 post-estrus. Vet. Res. Commun. 6, 199-204.

Long, G.G., Diekman, M.A. \& Scheidt, A.B. (1988) Effect of zearalenone on days 7-10 post-mating on intrauterine environment and migration of embryos in sows. J. Anim. Sci. 66, 452-458.

Mirocha, C.J., Harrison, J., Nichols, A.A. \& McClintock, M. (1968) Detection of a fungal estrogen (F-2) in hay associated with infertility in dairy cattle. Appl. environ. microbiol. 16, 797-798.

Mirocha, C.J., Pathre, S.V., Behrens, J. \& Schaverhamer, B. (1978) Uterotropic activity of cis and trans isomers of zearalenone and zearalenol. Appl. environ. microbiol. 35, 986-987.

Mitton, A., Collet, J.C., Szymanski, J. \& Gousse, R. (1975) Avortements dans un elevage ovin et presence de zearalenone dans l'alimentation. Rev. Med. Vet. 126, 813-820.

Smeaton, D.C., Hockey, H-U.P. \& Towers, N.R. (1985) Effects of facial eczema on ewe reproduction and ewe and lamb live weights. Proc. N.Z. Soc. Anim. Prod. 45, 133-135.

Smith, J.F., Jagusch, K.T., Brunswick, L.F.C. \& Kelly, R.W. (1979) Coumestans in lucerne and ovulation in ewes. N.Z. Jl agric. Res. 22, 411-416.

Smith, J.F., di Menna, M.E. \& McGowan, L.T. (1986) Effect of Fusarium culture and zearalenone on the reproductive performance of ewes. Proc. N.Z. Soc. Anim. Prod. 46, 255-258.

Smith, J.F., di Menna, M.E., McGowan, L.T., Peterson, A.J., Parton, G., Shanley, R. \& Duganzich, D.M. (1987) Effect of zearalenone on ovulation rate and plasma FSH in the ewe. Proc. Endocr. Soc. Aust. 30, suppl. 2 S2(14), abstr.

Received 1 August 1989 